\title{
Oral contraceptive and acute intestinal ischemia with mesenteric venous thrombosis: a case report
}

\author{
Aude Béliard' \\ Lucie Verreth ${ }^{2}$ \\ Pascale Grandjean ${ }^{2}$ \\ 'Department of Obstetrics and \\ Gynaecology, Centre Hospitalier \\ du Bois de l'Abbaye (CHBA), Liege, \\ Belgium; ${ }^{2}$ Department of Obstetrics \\ and Gynaecology, Centre Hospitalier \\ Régional (CHR) Mons Hainaut, Mons, \\ Belgium
}

This article was published in the following Dove Press journal:

Open Access Journal of Contraception

27 January 2017

Number of times this article has been viewed
Background: Venous thrombosis is a serious complication of combined contraceptive usage. However, mesenteric venous thrombosis and intestinal necrosis are infrequently seen in women using oral contraceptives, and in such cases diagnosis is often delayed.

Case presentation: We report the case of a 38-year-old obese female patient who presented with acute abdominal pain. A bowel infection was first diagnosed and treated with antibiotics. Contrast-enhanced tomography of the abdomen revealed diffuse ischemia of the small intestine with superior mesenteric thrombosis. Laparotomy with segmental resection of both small and large bowel was performed. No predisposing factor of mesenteric venous thrombosis was demonstrated except association of the combined contraceptive with obesity.

Conclusion: This report highlights the need for clinicians to suspect venous mesenteric thrombosis in women of reproductive age with acute abdominal pain and poor physical findings. Detailed personal history including prescriptions should help to quickly and accurately determine the problem.

Keywords: hormonal contraceptive, deep venous thrombosis, superior mesenteric vein, obesity, bowel infection

\section{Introduction}

Venous thrombosis is the result of stagnation of blood flow, vascular injury, and hypercoagulability (ie, Virchow's triad). The risk of venous thrombosis associated with the estrogen component of combined hormonal contraceptives has been reported and debated since the 1960s. Hormonal contraceptives affect a large number of hemostatic variables: ethinylestradiol induces a rise in factor VII activity, prothrombin fragment $1+2$, and resistance to the anticoagulant action of activated protein C. ${ }^{1}$ The prothrombotic effect of the estrogen component ethinylestradiol in combined contraceptives is influenced by the progestogen component present in these preparations.

Venous thromboembolism, although rare, remains one of the serious adverse consequences of hormonal contraception. Most venous thrombotic events secondary to contraceptives usually manifest as deep vein leg thrombosis and pulmonary embolism. Pelvic, cerebral, and retinal veins are infrequent sites of thrombosis.

We report a case of superior mesenteric vein thrombosis (MVT) associated with the use of combined hormonal contraceptives. This led to diffuse ischemia of the small intestine.
Correspondence: Aude Béliard Department of Obstetrics and Gynaecology, CHBA Rue Laplace 40, 4100 Seraing, Liege, Belgium

Tel +32 43387374

$\mathrm{Fax}+3243387379$

Email abeliard@chu.ulg.ac.be 


\section{Case report}

A 38-year-old nulliparous obese female patient consulted her general practioner for diffuse abdominal pain with fever. A bowel infection was diagnosed. She went back home with an antibiotic prescription. The treatment did not improve the symptoms. Two weeks later, she presented to the emergency department of the regional hospital with acute abdominal pain without nausea or vomiting. She had a body mass index (BMI) of $43 \mathrm{~kg} / \mathrm{m}^{2}$ and smoked five cigarettes per day. She had stopped hormonal contraception 5 years ago. She had some combined oral contraceptive (COC) tablets $(20 \mu \mathrm{g}$ ethinylestradiol + gestodene) left at home and had decided to restart contraception 4 months ago without consulting her general practitioner or gynecologist. She had no personal or familial history of thrombosis. She had no previous medical condition and was not on any medication except her pill. On physical examination, she was afebrile and had diffuse abdominal pain with peritoneal signs. Laboratory examination showed increased C-reactive protein level of $102.5 \mathrm{mg} / \mathrm{L}$ (normal range, $<5.0 \mathrm{mg} / \mathrm{L}$ ) and $\mathrm{LDH}$ level of $370 \mathrm{U} / \mathrm{L}$ (normal range, 125-243 U/L). A computerized tomographic scan with intravenous contrast of the abdomen was performed. An acute venous mesenteric thrombosis with diffuse ischemia of the small intestine was identified.

The patient was anticoagulated with intravenous heparin. A laparotomy was performed which revealed small intestine ischemic necrosis and a mass on the transverse large bowel. A resection of $2 \mathrm{~m}$ of small intestine was performed, followed by temporary ileostomy as well as transverse colectomy with end-to-end anastomosis. Reanastomosis of the small intestine was performed 1 month later. At histopathologic examination of the large transverse bowel mass, acute inflammatory and fibrotic subserosal changes were observed. COC was stopped at the time of admission. Medroxyprogesterone acetate injection was given 1 month later at the time of small intestine reanastomosis, and the patient was switched to oral progestin 3 months later. Evaluation for prothrombotic conditions including protein $\mathrm{C}$, protein $\mathrm{S}$, antithrombin deficiency; factor $\mathrm{V}$, prothrombin gene mutation, lupus anticoagulant, and antiphospholipid and anticardiolipin antibodies were all negative. The patient gave written informed consent for her data to be used in this publication.

\section{Discussion}

Epidemiological studies indicate that venous thromboembolism rates in noncontraceptive users of reproductive age approximate one per 10,000 women-years in 20 -year-old women, and five per 10,000 in women of
40 years; rates in oral contraceptive users are in the range of 4-12/10,000 women per year. ${ }^{2}$ In comparison, venous thromboembolism rates in pregnancy approach 29/10,000 overall and may reach $300-400 / 10,000$ in the immediate postpartum period. ${ }^{3}$

The superior mesenteric vein is a rare site of thrombosis. MVT almost always involves the distal small intestine ileum or jejunum (superior mesenteric venous drainage) and rarely involves the colon (inferior mesenteric venous drainage). The inferior mesenteric venous distribution is less commonly involved - this is possibly related to collateral flow. Acute thrombotic occlusion of one or more mesenteric veins reduces perfusion pressure. If the venous arcades and vasa recta are involved and if the venous return from the bowel wall is completely occluded, bowel infarction will occur. Direct injury (trauma, surgery, pancreatitis, etc), local venous congestion (portal hypertension/cirrhosis of the liver, congestive heart failure, hypersplenism), and hypercoagulability caused by thrombophilia or malignancy are also risk factors for MVT. Incidence of MVT is estimated to be 2.7 per 100,000, and COC-related MVT accounts for $4 \%-5 \%$ of total MVT. ${ }^{4}$ Superior MTV associated with hormonal contraception was first described in 1963, 3 years after the approval of the first oral contraceptive pill in the United States. ${ }^{5}$ Diagnosis is sometimes difficult because of nonspecific abdominal symptoms and physical examination, and delayed diagnosis causes extensive intestinal ischemia with a high risk of mortality. Prompt recognition is important because early systemic anticoagulation therapy may limit progression of the thrombotic process and allow nonoperative management. Diagnosis should be suspected when acute abdominal symptoms are disproportional to the physical findings. Detailed past medical or familial history of thrombosis and prescriptions used should be taken. Contrast-enhanced abdominal computerized tomography facilitates diagnosis and is considered as a gold standard. ${ }^{6}$ It can accurately detect portal vein, ovarian vein, and MVTs.

The treatment is predominantly conservative with systemic anticoagulation. Surgical exploration is limited to patients with signs of bowel infarction. Discontinuation of COC is mandatory. Full hypercoagulability screening should be performed.

In the WHO Medical Eligibility criteria, ${ }^{7}$ obesity is not considered as a limiting factor for using COC. However, in recent data, the risk of venous thrombosis has been shown to be increased in COC users with morbid obesity in comparison with normal-weight contraceptive users, and the risk continues to increase with increasing BMI. ${ }^{8}$ It is important to 
consider this increased risk with obesity when recommending a contraceptive method.

In the case described here, the patient decided to reuse COC without any health professional's advice. As unintended pregnancy in obese women leads to increased health risk, use of progestin contraception or intrauterine device is recommended. These methods do not expose the woman to potential risk associated with estrogen-containing contraceptives. Although venous thrombosis may occur at any time, thrombotic risk is maximal during the first 12 months of using or reusing COCs, and this is attributed to exposure to a new risk factor, especially if other risk factors are also present, such as in this case, age, morbid obesity, and smoking. The risks of hormonal preparations related to venous thrombosis disappear when COC is discontinued. ${ }^{9}$

\section{Conclusion}

Intestinal ischemia and necrosis caused by mesenteric venous thrombosis is a rare complication of combined contraceptives. Clinicians should consider intestinal ischemia in women on COC developing sudden severe abdominal pain without any other obvious cause of pathology.

\section{Disclosure}

The authors report no conflicts of interest in this work.

\section{References}

1. Kluft C, Lansink M. Effect of oral contraceptive on haemostasis variables. Thromb Haemost. 1997;78(1):315-326.

2. Lidegaard Ø. Hormonal contraception, thrombosis and age. Expert Opin Drug Saf. 2014;13(10):1353-1360.

3. Jacobsen AF, Sandset PM. Venous thromboembolism associated with pregnancy and hormonal therapy. Best Pract Res Clin Haematol. 2012; 25(3):319-332.

4. Hmoud B, Singal AK, Kamath PS. Mesenteric venous thrombosis. JClin Exp Hepathology. 2014;4(3):257-263.

5. Reed DL, Coon WW. Thromboembolism in patients receiving progestational drugs? N Engl J Med. 1963;269:622-624.

6. Yang S, Fan X, Ding W, et al. Multidisciplinary stepwise management strategy for acute superior mesenteric venous thrombosis: an intestinal stroke center experience. Thromb Res. 2015;135(1):36-45.

7. Department of Reproductive Health, World Health Organization. Medical eligibility criteria for contraceptive use. Fifth edition, 2015. Available from: http://www.who.int/reproductivehealth/publications/family_planning/Ex-Summ-MEC-5/en/. Accessed August 31, 2015.

8. Horton LG, Simmons KB, Curtis KM. Combined hormonal contraceptive use among obese women and risk for cardiovascular events: a systematic review. Contraception. 2016;94(6):590-604.

9. van Hylckama Vlieg A, Helmerhorst FM, Vandenbroucke JP, Doggen CJ, Rosendaal FR. The venous thrombotic risk of oral contraceptives, effects of oestrogen dose and progestogen type: results of the MEGA case-control study. Br Med J. 2009;339:2921-2929.
Open Access Journal of Contraception

\section{Publish your work in this journal}

Open Access Journal of Contraception is an international, peerreviewed, open access, online journal, publishing original research, reports, reviews and commentaries on all areas of contraception. In addition to clinical research, demographics and health-related aspects, the journal welcomes new findings in animal and preclinical studies

\section{Dovepress}

relating to understanding the biological mechanisms and practical development of new contraceptive agents. The manuscript management system is completely online and includes a very quick and fair peer-review system. Visit http://www.dovepress.com/testimonials.php to read real quotes from published authors. 